\title{
Global trends in audit quality, supervision, and standard setting
}

\author{
Janine van Diggelen
}

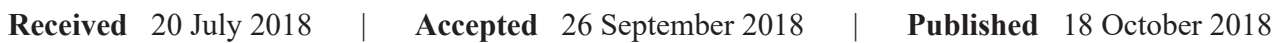

The following topics are currently high on the agenda of IFIAR: global trends in audit quality (and measuring audit quality) and global trends in supervision and standard setting. In her key note speech, Janine van Diggelen provided her personal insights and perspectives on these issues.

\section{IFIAR's mission}

IFIAR's mission is to globally improve audit quality. Audit quality is primarily the responsibility of audit firms and provides a cornerstone of the international financial stability and economic growth. Investors and capital markets rely on auditors to assure the integrity of financial statements and to create the necessary confidence for making important financial decisions. In our interconnected world, audit quality issues are not unique to any jurisdiction. Therefore, issues with audit quality require a global response. The objective to improve audit quality lies at the core of IFIAR's mission.

First of all, IFIAR fulfills its mission by focusing on and challenging the global CEOs and audit leaders of the big six audit firms regarding inspection outcomes of listed Public Interest Entity (PIE) audits, on outcomes of root cause analysis and on the effectiveness of their change programs. Secondly, IFIAR interacts with representatives of the global investor and audit committee community. Through running tendering processes, selecting the audit firms and evaluating the quality of the auditor they have an important role when it comes to enhancing audit quality by stimulating competition on quality rather than on price in the audit market. The third main workstream of IFIAR is its engagement with the international audit and ethical standard setters, as standards could play an important role in further driving consistency in the execution of high quality audits and in auditor behavior.

\section{Defining and measuring audit quality}

But how does IFIAR measure the current trend in audit quality globally and how does it define audit quality? IFIAR defines audit quality from the perspective of the audit objective, which is: to provide a high level of assurance that the financial statements give a true and fair view and are free from material misstatements. Internationally, we have agreed on how a so-called 'high-quality audit' should be conducted that meets this objective. The outcome is the suite of International Standards on Auditing the ISA's - or other generally accepted auditing standards like the PCAOB standards. When signing the auditor's report, auditors explicitly state that they have carried out the audit in accordance with the applicable auditing standards. This forms the basis for investors and other users to have confidence in the auditor and his opinion.

As the auditing standards reflect the internationally agreed minimum requirements for carrying out high quality audits, audit regulators across the globe consider these as the bar for measuring audit quality. So does IFIAR. Through its annual Inspection Findings Survey, IFIAR collects and summarizes the nature and extent of material findings resulting from listed Public Interest Entity (PIE) audit file inspections carried out by its members. It also reports on the percentage of deficient audits with at least one material finding resulting from these inspections. A material finding is defined as a lack of sufficient and appropriate audit evidence to support the audit opinion issued. This does not necessarily mean that the audited financial statements are materially misstated, but it means that uncertainty exists, as the level of assurance based on the work done by the auditor is not high enough.

\section{Audit quality and compliance}

Some of you may think: but isn't there more to measuring audit quality then compliance with the standards? What about the expectations that investors, audit committees and other stakeholders have of a high-quality audit and what about the various audit quality indicators that are being studied, identified and reported on in various projects, also by several regulators? Think about the work 
done by the PCAOB on potential audit quality indicators to support audit committees, the Audit Quality Indicators Pilot by the Canadian Regulator Canadian Public Accountability Board (CPAB), that also includes companies' management deliverables as Audit Quality Indicators. And what about the dashboard with the three pillars control, behavior and culture and internal supervision that the AFM uses to report on the progress of audit quality improvement programs? Going forward, IFIAR will explore whether it can build upon the work done by its members and consider developing a framework for assessing audit quality more broadly, which would include culture, audit quality control processes and project management at the firms. In my view such a framework could provide valuable additional insights, particularly in comparing firms, which can be a driver of audit quality in itself. Such a framework could also be very useful for audit committees, given their responsibilities. At the same time, we should realize that good ratings on audit quality indicators not necessarily mean that an individual audit actually provides the required high level of assurance. Even so, I do hope that IFIAR, together with the firms and the investor and audit committee community, will be able to develop a workable framework with audit quality indicators at the firm and engagement levels, that can be used and tested in practice in addition to the current measurement of audit quality. This would better reflect the investments and progress made to date by the firms which the current measurement tool used by IFIAR does not provide.

\section{What is actually the current trend in audit quality globally?}

IFIAR's 2017 Inspection Findings Survey, which was published in early March 2018 (IFIAR, 2018), showed that 40 percent of the listed PIE audits that were inspected had at least one material finding, compared to 41 percent in the 2016 survey (IFIAR, 2017) and 47 percent in the 2014 survey (IFIAR, 2015). Based on the surveys it is not possible to do a statistical trend analysis on audit quality, mainly due to changes in members underlying inspection programs from year to year. Nevertheless, the observed trend overtime provides valuable information on whether audit quality globally is heading in the right direction. Although the percentage went down, there is a flattening declining curve since 2014 and progress is not experienced in all jurisdictions at the same rate.

The latter becomes more evident when we look at the 25 percent reduction target concerning deficient audits. IFIAR's Global Audit Quality Working Group has challenged the global big six audit firms to reduce the percentage of deficient audits by at least 25 percent collectively in the jurisdictions of the Global Audit Quality Working Group's members in a four-year time period. The global leadership of the Big 6 audit firms have in turn rolled out the reduction target to the member firms in their networks in these same jurisdictions. The 2017 survey report reflects the progress of the Big 6 firms at the measurement period's mid-point and reports a deficiency rate of 30 percent, bringing the deficiency rate very close to the target of 29 percent that was set for the 2019 Survey. The 30 percent deficiency rate for Global Audit Quality Working Group jurisdictions turns out to be considerably lower than the average deficiency rate for the non-working group IFIAR members, which is 63 percent. The reasons for these differences could be many: apart from differences in inspection programs and the number of listed PIEs that are inspected, it could also relate to the firms not enforcing the reduction target throughout their whole network and firms first rolling out quality improvement programs in the jurisdictions with most listed PIEs which might result in other jurisdictions lagging behind. IFIAR is in the process of discussing the next steps in the reduction target with the global leadership of the Big 6 audit firms.

\section{Consistent inspection findings}

Contrary to the deficiency rate, the top-3 types of inspection findings are globally quite consistent, being:

Accounting estimates. Most findings related to failure to assess the reasonableness of assumptions, including consideration of contrary or inconsistent evidence.

Internal control testing. The most common types of findings were the failure to obtain sufficient persuasive evidence to support reliance on manual internal controls and the failure to sufficiently test controls over, or the accuracy and completeness of, data or reports produced by management.

Revenue recognition. In previous years this was an area with high rates of findings but showed comparatively lower findings in the 2017 survey. Consistent with prior years, the type of revenue recognition findings reported most frequently related to the failure to appropriately assess and respond to the risk of fraud.

Based on the survey outcomes we can conclude that the level of and persistence in findings remain too high. Consistency in the execution of high-quality audits is the big issue at the firm and global level. When there is a deficient audit, many things have not worked properly: the supervision and review, the partner involvement and the Engagement Quality Control Review (EQCR) have all failed to prevent a deficient audit. This implies that the firm's quality control systems and procedures are not robust enough to sufficiently prevent deficient audits from occurring. Given the flattening curve in the percentage of deficient audits, I think, much more needs to be done and that needs to be done expeditiously.

\section{Pace of improvement too slow}

As progress in improvement is slowing down, it seems that the quick wins and low hanging fruit have been taken by implementing things like more training, better and 
more standardized tooling, reducing partner workload and requiring inflight or hot reviews. The change programs address the tone at the top, culture and behavior, governance and process and project management in the firms. However, they do not yet lead to demonstrated improvement of audit quality on individual audits. Why is that? This is partly due to the time lag between audit and inspection reporting cycles and because cultural and behavioral change requires time. But the main reason, in my view, is that the measures taken through the change programs do not sufficiently and holistically address the underlying root causes.

First of all, firms need to further deepen their root cause analysis, not only at audit file level, which firms tend to do, but also at audit firm and audit profession level for identifying the more systemic and structural issues resulting from the issuer-pays multidisciplinary partner-apprentice model. The way forward is not combatting symptoms but identifying and addressing underlying root causes that drive behavior and decision making at all levels in the firm. Firms should use behavioral experts in doing so.

Secondly, audit firms should focus more on how to effectively achieve a cultural and behavioral change - in my view the most important driver for audit quality. More in depth analysis and insights into, for example, informal organizational structures, implicit beliefs about what behavior is expected in what circumstances by audit team members (which not necessarily aligns with what management would expect) are important. Is the EQCR role perceived as very important and do EQCR partners receive high esteem for this role? Is tone at the top (also from the partners) supported by 'practice what you preach'? Does quality really come first in the heat of a difficult discussion with the audit client? Are signals of suspected fraud or unusual transactions being reported to authorities, if needed?

Thirdly, an area of focus should be project management: how to manage the engagement process in terms of best timing of doing the audit work and how to manage the timely deliverables by the audit client.

Another area of focus I would like to mention is whether there are sufficiently experienced team members carrying out the audit in the busy season, and if not: how can that be solved? We all know that too much time pressure and multitasking leads to inefficiencies and ineffectiveness with the risk of poor judgements.

Last but not least, the quality control management process should be strengthened from cradle to grave, so from client portfolio risk assessments to the EQCR. Implementing sufficient preventative checks and balances throughout the audit process is key for creating a safe learning environment, opposed to having a culture of fear not knowing whether there could be significant quality issues popping up when the audit worked on is selected for a file review. A final step in strengthening quality control management is monitoring progress and effectiveness through audit quality indicators, other key performance indicators and milestones to be able to make timely adjustments when needed.

\section{More timely standards needed}

There is still one other area that I would like to highlight that could contribute to improvement of audit quality. Given the persistence in the top three inspection findings globally, standard setters should focus more on how the standards can further drive professional skepticism, compliance and consistency in auditor behavior in these key areas of the audit. The last couple of years, the standard setters started to look into these issues. But to keep the standards relevant, more timely changes to the standards are needed, in order to better meet global capital markets' needs. This also applies to IT innovations and how these disruptive enablers can make audits more effective and efficient including in relation to fraud and unexpected bankruptcies. To achieve this, the strategic focus of the standard setters need to be reconsidered in order to ensure relevant, timely and effective auditing and ethical standards going forward. The proposals to reform the international auditing and ethical standard setting governance and oversight as consulted by the Monitoring Group are meant to respond to these concerns.

\section{Quality first!}

Let me conclude by summarizing how I see the way forward: put quality first! To achieve this, a deep root cause analysis at firm and audit sector level is needed, from the perspective that structure follows strategy. Ensuring that strategies and policies, including commercial policies, are fully aligned with high-quality audits while meeting auditing standards is understood as a minimum requirement and not just as an aspirational benchmark. Root cause analysis and resulting measures and change programs should focus on culture, structure including the business model, sufficient talent, process and project management to support the strategies of delivering high quality audits consistently throughout the firms and the profession. And last but not least: the standard setters should focus on how their standards could further contribute to improvement of audit quality and how new technologies could innovate audits and make them more effective going forward.

\section{Summary of the discussion}

Culture is of paramount importance in realizing a high-quality audit. Procedures and processes are developed to improve audit quality, but their effectiveness only becomes visible when people are actually being confronted with dilemmas. Is quality really put first in those situations? This required match is slowly improving, but the tone at the top has to be heard throughout the organization, at all levels. Everyone must be aware of the same concept of quality at the outset of an audit engagement. To increase quality maybe the audit firm's business model 
has to be changed? Van Diggelen: "That won't help if we haven't first analyzed what elements of those models are not driving the quality oriented culture and behavior we need". And is the negative focus of the regulator not detrimental for the 'expectation gap'? Van Diggelen is familiar with the allegation by the profession that the regulator is fueling the trust crisis. However, she states that the profession will have to manage the expectation gap even better. 'We're in this together' is the conclusion of the discussion. IT could potentially play an important role in narrowing the expectation gap. Nowadays all transactions can be tested efficiently instead of only a sample. The use of big data and external data sources together with innovative analytical audit tools could provide for more specific and conclusive audit evidence and as such contribute to higher levels of assurance that the financial statements are free from material misstatement due to fraud.

\section{References}

- Canadian Public Accountability Board (CPAB). Audit quality indicators. Final Report. http:/www.cpab-ccrc.ca/Documents/Topics/ Audit\%20Quality\%20Indicators/AQI\%20Final\%20Report\%20EN.pdf

- Canadian Public Accountability Board (CPAB). Audit committee guide to audit quality indicators. http://cpab-ccrc.ca/Documents/ Topics/Audit\%20Quality\%20Indicators/AQI\%20Guide\%20en.pdf

- International Forum of Independent Audit Regulators (IFIAR) (2018, March 8) Survey of inspection findings 2017. https://www. ifiar.org/activities/annual-inspection-findings-survey/

- International Forum of Independent Audit Regulators (IFIAR) (2017, March 3) Survey of inspection findings 2016. https://www. ifiar.org/activities/annual-inspection-findings-survey/
- International Forum of Independent Audit Regulators) (IFIAR) (2015, March 3) Survey of inspection findings 2014. https://www. ifiar.org/activities/annual-inspection-findings-survey/

- Public Company Accounting Oversight Board (PCAOB) (2015) Docket 041: Concept Release on Audit quality indicators. https:// pcaobus.org/Rulemaking/Docket 041/Release_2015_005.pdf

- Netherlands Authority for the Financial Markets (AFM) (2017, June 28): Quality of PIE audit firms 2017 - part 1 - General Conclusions (page 18). https://www.afm.nl/en/professionals/nieuws/2017/juni/ kwaliteitslag-oob 